Daniela Remião de Macedo Fotógrafa

Visuais com ênfase em Poéticas Visual no IA/UFRGS. no IA/UFRGS

Mestre em Ciência

pela PUC-RS

(1999). Docente do

Instituto Federa

do Rio Grande

egrante do grupo

LUMEN-UFRGS

Pesquisa processos

fotográficos

históricos e

hibridismo da

fotografia con

outras linguagens

$\begin{aligned} \text { exposições } & \\ \text { intisticas. Realizou } & \end{aligned}$

individuais e

coletivas no Rio

Grande do Sul, Rio

de Janeiro, Mato

Grosso, Bahia

e Amazonas.

Eduardo Vieir

Doutor em Artes

Plásticas-Universite

Paris 1 (Panthéon-

Sorbonne). Master

of Fine Arts

- Brooklyn Colleg

of New York.

Professor associado

e Coordenador

área de Fotografia

\section{Os tempos da arte fotográfica: um ensaio em Paris}

\section{The times of photographic art - an essay in Paris}

Resumo: Este trabalho visa um registro da pesquisa em andamento junto ao PPG em Artes Visuais e propõe uma reflexão sobre questôes que envolvem a fotografia e o tempo. São abordadas possibilidades da fotografia artística que permitem expandir o tempo do fazer fotográfico, incorporando temporalidades de todo o processo de criação, desde a teatralização fotográfica na pré-produçāao, a representação do tempo na fotografia, até a seleção e edição das imagens na pós-produção. Por fim, é apresentado o resultado de um ensaio inspirado em Edgar Degas, em uma série de fotografias que compõe uma narrativa, envolvendo a fotografia, a pintura e a dança, onde questões do tempo foram consideradas.

Abstract: This paper aims to record ongoing Masters research at the Postgraduate Program in Visual Art/UFRGS, RS, Brazil and proposes reflection on issues involving photography and time. Possibilities of art photography are explored that allow expanding the time of making photography, incorporating temporalities into the whole creative process, from pre-production photographic theatralization, to representing time in photography, up to the selection and editing of images in post -production. In the end, we present the result as an essay inspired by Edgar Degas, es of photographs that compose a narrative, involving photography, painting .

Words: Photography: Time: Photographic Theatralization: Narrative: Edgar De
O estudo do desenvolvimento histórico da Fotografia nos revela que ela só é considerada artística quando se assemelha à Pintura. A fotografia não se limitou, porém, a plagiar ou assimilar aspectos da pintura, o que a pintura também faz na direção inversa, segundo Belting (2014), mas foi buscar de empréstimo o olhar, para conferir às suas imagens maior profundidade e um significado mais universal, com o qual transcendesse os seus limites técnicos enquanto meio. E da mesma forma que os pintores, os fotógrafos também foram em busca de se libertarem das regras e transparecerem sua sensibilidade ao potencial da imagem fotográfica de se tornar Arte.

São vários os artistas visuais que ao longo da história contribuíram para moldar o olhar moderno, começando por Bayard até artistas contemporâneos. E entre tantas referências, chama-nos a atenção especialmente Edgar Degas, que mais que qualquer outro pintor do século XIX, compreendeu o que significa ver em termos fotográficos, compreendendo tão bem a fotografia e todas as suas possibilidades. E que, mesmo com formação clássica, se permitiu a liberdade de fugir à representação eloquente em termos tradicionais e subverter o realismo banal por uma filosofia de mise-en-scène'.

Usualmente, definimos a fotografia como um recorte de tempo e espaço. A fotografia, como todas as artes visuais, suscita muitas questões sobre o espaço, pois diz respeito àquilo que efetivamente é visível, sendo ela própria um espaço, uma superfície que oferece a representação de um outro espaço, aquele que faz parte do que chamamos de realidade. Quando ao tempo, segundo Ronaldo Entler (2007), mesmo a fotografia sendo estática, se insere na dinâmica de um olhar que segue na direção não apenas do passado, mas de uma transcendência. Entler salienta que toda fotografia reconstrói lugares e personagens com base em códigos estabelecidos por al- no IA/UFRGS. Docente do Programa de Pósgraduação em Artes Visuais da UFRGS Realizou diversas exposições individuais e coletivas: Pintura e Objetos no MARGS-RS no Museu Brasileiro da Escultura-SP, $2003 \mathrm{e}$ na Gelerie Ficher-RohrBasel, Suiça, 2007. 
guma tradição. A interpretação efetiva da imagem não nos conduz a alguém, mas a um papel. E a imagem parte sempre de um lugar situado no passado, mas aponta também na direção de uma virtualidade, constitui uma encenação quase atemporal dentro da qual um vasto universo de atores pode ser inserido.

Gastaldoni (2005) afirma que, se a luz é a matéria-prima da fotografia, o tempo é a sua alma. E o tempo pode se desdobrar em muitos tempos. Dessa forma, compreende-se que, além do tempo cronológico que reside na imagem, outros tempos se desencadeiam e se emaranham. E esses tempos compreendem também o pré, durante e pós ato fotográfico. Assim, a teatralização da realidade e todos os preparativos antes da tomada da cena, o porquê da existência daquela imagem, seu preparo, a máscara social dos personagens, a duração da captura até o momento da seleção e da emulsão trazer à superfície os sujeitos fotografados incorporam em si meandros de temporalidade. Essas situações latentes no próprio tempo do fazer fotográfico introduzem em nós a poética das imagens fotográficas.

Refletindo sobre o ato fotográfico, embora a origem técnica da fotografia tenda a caracterizar seu processo de criação como um exercício de precisão, temos aprendido a pensar a criação fotográfica como um processo que se constrói em etapas. Dessa forma, o fotógrafo tem a chance de realizar várias tomadas de uma cena para, posteriormente, escolher aquela que julgará bem-sucedida, da mesma forma como o pintor realiza estudos e esboços para chegar à sua obra acabada. Os estudos e esboços de um artista, segundo Ronaldo Entler (2007), não diminuem o valor de seus resultados.

E assim, com inspiração na arte e na liberdade de Edgar Degas, e procurando-se evidenciar os vários tempos envolvidos no fazer fotográficos, foi realizado um ensaio na cidade de Paris, e o resultado dessa experimentação é apresentado no final deste trabalho.

\section{A FOTOGRAFIA COMO ARTE}

No imaginário do século XIX era forte a vinculação entre a fotografia e sua função de reprodução analógica. A fotografia é inventada para satisfazer as crescentes necessidades de perfeição e de reprodutibilidade das imagens. O que permitiu à técnica de Daguerre merecer reconhecimento, entre outras técnicas de reprodução gráfica já existentes na época que resolviam em certa medida ambas necessidades, foi exatamente sua perfeição e exatidão como "espelho da natureza". Esses valores de perfeição, exatidão, automatismo, marcaram não apenas a invenção da fotografia, mas também a preeminência de um tipo de fotografia (FLORES, 2011). Assim, o principal problema que a fotografia enfrenta naquele período por sua reprodutibilidade técnica é cair, simultaneamente, em paradigmas epistemológicos contraditórios, como a ciência e a arte. Se pela sua capacidade documental a fotografia podia ser vista como "ciência", por sua potencialidade "expressiva" podia ser considerada "arte", ou ainda, dada sua evidente inserção nos processos de reprodução mecânica, a fotografia poderia também ser considerada simplesmente tecnologia.

No entanto, a fotografia de Bayard constata que a possibilidade da criação na fotografia é inerente a ela, desde o princípio. Em um gesto irônico motivado por um sentimento de ressentimento, Hippolyte Bayard distribuiu uma foto na qual ele próprio aparece afogado e no verso um texto supostamente escrito por uma testemunha anônima. O afogado, esclarece Flores (2011), poderia ser considerado um antecedente visionário da performance e do autorretrato pós-modernos. E já em 1841, Bayard comprova que as fotos 
não são apenas tiradas, mas feitas. A sutil e clara diferença entre tirar e fazer uma fotografia marca dois caminhos diferentes, exemplificados por Daguerre e Bayard.

Segundo Flávia Flores (2011), se entendemos o daguerreótipo como o início de uma linha técnica cuja intenção central é a "verificação da realidade", o caminho iniciado por Bayard poderia ser entendido como a "construção de uma realidade". E somente podemos entender o trabalho de Bayard como o de alguém sensível ao potencial da imagem fotográfica de se tornar Arte. Consciente ou não do que $O$ afogado implicava, Bayard abre caminho para uma arte fotográfica que explora a imaginação a custa da proposta de realidade.

\section{TEATRALIZAÇÃo FOTOGRÁFICA}

O historiador de fotografia Jean-Claude Lemagny, citado em (SOULAGES, 2010), distingue duas tendências da fotografia: a "fotografia direta", que explora a realidade que se apresenta ao fotógrafo, como a reportagem, o retrato, a paisagem; e a "fotografia encenada", a fotografia subjetiva, manipulada, autônoma, exploração da realidade do próprio meio fotográfico. Essa distinção indica os dois pólos, o objeto e o sujeito, entre os quais hesitam e se orientam as fotos - a "fotografia direta" deixaria a escrita para o objeto luminoso, e para o fotógrafo, a responsabilidade do enquadramento; já a "fotografia encenada" seria escrita por um sujeito esclarecido, responsável pela composição.

De acordo com Soulages, na teatralização da imagem um fotógrafo pode ser tentado por duas direções: a da publicidade, que constitu um instante eternizado de uma peça de teatro engajada em proveito de uma produção e de um consumo determinados, e a da obra de arte, em que o objeto fotográfico é desviado de seu sentido mundano para adquirir um sentido fotográfico.

PARALEL@3!
Fotografar pode gerar vários tipos de comportamento: ou ver com a discrição aparente do voyeur, ou mostrar-se com a exuberância do exibicionista. Em todos esses casos, é sempre constituir um teatro do qual se é o diretor, do qual se é por certo tempo, o Deus ordenador: dão-se as ordens, chama-se à cerdem tempo, o Deus ordenador: dão-se as ordens, chama-se à ordem, é, então, ouvido e obedecido; poder decorrente da máquina que detém o tempo e parece captar o ser ou, pelo menos

uma das formas instantâneas do ser. (SOULAGES, 2010, p. 67).

A fotografia deve ser, então, não só encenação como invenção, e o fotógrafo, o criador. E essa liberdade exploradora e criadora é verificada entre os fotógrafos desde o início da fotografia.

A teatralização na pintura foi exportada para o campo da fotografia de forma modificada, mas não totalmente transformada, segundo Soulages. Nos retratos fotográficos de Julia Cameron essa questão se evidencia. Ela queria fotografar com a mesma qualidade artística com que o melhor pintor teria pintado ou o maior diretor de teatro teria feito representar. Todo retrato é uma encenação. E Cameron, com sua personalidade e escolhas artísticas, técnicas e ideológicas, recusou-se a adotar uma teatralização fotográfica realista, indo de encontro à critica fotográfica tradicional do século XIX. A fotógrafa mostra, assim, já desde o início da história da fotografia, que ser artista é escolher, e que o mais importante não é o objeto a ser fotografado, mas a maneira fotográfica de guardar suas aparências visuais para produzir o fotográfico.

Há sempre uma encenação do fotógrafo, não apenas nas fotos de pessoas que sabem que estão sendo fotografadas, mas também nas de pessoas anônimas tiradas às escondidas. Diante da foto de um anônimo, não podemos saber se trata-se realmente de um anônimo espionado ou de uma pessoa prevenida, e que dessa forma representa. 
Alguns fotógrafos se opõem explicitamente à estética de Cartier -Bresson e constroem sua obra contra a doutrina do instante decisivo A fotografia não é mais citação da realidade, mas história encenada, afirma Soulages.

Willian Klein rejeita o instante decisivo, substituindo pelo sujeito que decide, e afirmando que todos os instantes são decisivos. Cabe ao artista, e não ao tempo, decretar o que será uma foto e decidir sobre isso.

$$
\begin{aligned}
& \text { Fotos automáticas, paparazzo, tabloide pastiche, arte bruta, antifoto, } \\
& \text { para começar. Eu não estava limitado por um formato fotográfico } \\
& \text { ou por tabus; Experimentava tudo. Granulado, desfocado, não } \\
& \text { enquadrado, deformação. Acidentes. Batia fotos ao acaso [...], } \\
& \text { fazendo esse procedimento render o máximo. Mergulhava de } \\
& \text { cabeça em tudo o que não devia fazer em fotografia [...] Tinha a } \\
& \text { impressão de que os pintores tinham se libertado das regras: por } \\
& \text { que não os fotógrafos? (KLEIN apud SOULAGES, 2010, p. 81). }
\end{aligned}
$$

Na aventura deliberada de Klein não há nenhum limite, a experimentação é total e só existe um modelo: a liberdade total dos pintores.

Segundo o artista Jeff Wall, citado em (BELTING, 2014), foi graças ao confronto com a arte conceitual que a fotografia reinscreveu a sua produção imaginal num plano de reflexão, caracterizado por uma intencionalidade declarada, na qual a ficção trabalha a par do carác ter analógico da reprodução técnica. Em suas fotografias, o artista faz um diálogo com a pintura, precursora da fotografia, com o cinema, que até certo ponto se tornou o seu herdeiro.

Hans Belting (2014) diz que os fotógrafos-artistas encenam o mundo, de forma a apoderar-se dele não só na imagem, mas no tema ou motivo, tornando-o assim matéria prima para a imaginação.

A fotografia aprendeu a aceitar o gesto cotidiano e eloquente como seu tema privilegiado. Nas últimas décadas, entretanto, o espontâneo passou a ser simulado por meio da pose. E percebemos que o realismo é, neste sentido, sempre uma construção, um diálogo com alguma tradição da arte mais do que com o real: é a reprodução de uma realidade que parece uma pintura, que parece um cenário, que parece uma fotografia.

\section{REPRESENTAÇÃO DO TEMPO NA FOTOGRAFIA}

Refletindo sobre o corte temporal efetuado na ação da fotografia se percebe que este é incapaz de anular por completo a sugestão do tempo e movimento nas imagens fotográficas. E com esse pensamento, Ronaldo Entler (2007) apresenta três possibilidades de representação do tempo na imagem fotográfica:

o tempo inscrito, com a inscrição do tempo no espaço sob a forma de um borrão conforme o objeto se desloque no espaço selecionado;

- tempo denegado, com a fotografia instantânea que de modo abrupto e forçoso retira o tempo da cena e prolonga a imagem do movimento congelado diante do nosso olhar, sem porém nos deixar de informar sua ação e poder esconder o movimento totalmente;

o tempo decomposto, com uma sucessão de instantes no tempo compondo uma única imagem ou uma série de imagens que se relacionam, podendo incorporar uma narrativa.

Temos aprendido a pensar a criação fotográfica como um proces so que se constrói em etapas, e que envolve uma série de escolhas, os equipamentos e materiais, os enquadramentos e instantes e, finalmente as imagens que serão editadas, ampliadas e exibidas ao público. Dubois diz que, quando a fotografia se reconhece como discurso, ela aprende também a explorar a relação entre imagens. Assim, ganha força a noção de ensaio, que pode às vezes ser entendida literalmente como revelação de um processo de pesquisa. O resultado é uma obra que explicita um percurso, portanto, a duração de um olhar, e aqui o tempo se faz 
representar por meio de sua decomposição numa série de imagens (ENTLER, 2007).

Essa possibilidade remonta às experiências cronofotográficas de Étienne-Jules Marey e Eadweard Muybridge, realizadas a partir de 1880. Marey registrando diversas frações do movimento numa mesma chapa fotográfica, trabalhando com um obturador que abre e fecha a passagem de luz sucessivamente ${ }^{2}$, e Muybridge detendo cada etapa da locomoção de um homem ou animal numa imagem distinta, alinhando um conjunto de câmeras ao longo do trecho a ser percorrido e disparando-as sequencialmente, com pequena defasagem de tempo ${ }^{3}$.

Podem-se reconhecer influências dos processos cronofotográficos em diversos artistas, como Degas, com sua série Bailarinas e alguns esboços de cavalos, realizados por volta dos anos de 1880; também em Marcel Duchamp, com o Nu descendo a escada (1912) e, de modo evidente, em quase todos os futuristas, ainda que o tenham negado, pelo peso da tradição que nega à fotografia tal valor de interpretação.

A estruturação sequencial de imagens está também na base de quase todas as experiências com narrativas visuais, incluindo o cinema e os quadrinhos. Aparece também numa longa tradição da pintura: as inscrições nas pirâmides que mostram a passagem dos faraós para uma vida após a morte, as cerâmicas gregas que contam feitos heróicos, as iluminuras medievais que relatam passagens bíblicas, além de dípticos e trípticos que podem também assumir uma forma narrativa.

Duane Michals não quer captar um acontecimento que ocorreu num dado instante, o momento decisivo, mas contar uma aventura que se desenvolve durante certo tempo, abre-se para a narração e para a ficção: por vezes aparece um anjo na foto, em decorrência das necessidades da história e, ao mesmo tempo, para mostrar que a fotografia capta as aparências às vezes invisíveis para o olho humano e não a simples realidade 4 .
A realidade das fotos não é a do mundo no qual se vive. Os fotógrafos devem se situar no mesmo plano que os pintores para abordar a questão da realidade, é uma das condições da possibilidade de que eles façam arte. E assim, Soulages (2010) reforça que o fotógrafo não tira fotos, ele as faz, evidentemente a partir dos fenômenos visíveis, sem com isso procurar ter deles uma restrição realista, mas, sobretudo, a partir das imagens psíquicas que ele inventa em si mesmo.

As narrativas fotográficas e ensaios rompem, assim, com a noção de criação fotográfica como golpe, decompondo o espaço e o tempo em uma série de imagens.

\section{A FOTOGRAFIA TEATRALIZADA DE EDGAR DEGAS}

Como pintor, as conexões de Degas com a fotografia são universalmente reconhecidas. No grande debate para decidir quais aspectos da pintura do século XIX são atribuíveis ao precedente fotográfico, Degas revela-se geralmente uma espécie de originador heróico do instantâneo, conseguindo por meados de 1870 a ilusão de vida capturada de passagem com cenas apreendidas como se pelo olho de um andarilho casual. A testemunha inadvertida, em meio a performances privadas tornadas públicas, nunca sabe da origem ou do resultado de uma cena, é absorvida por incongruências às quais, momentaneamente, recebeu acesso público.

O interesse de Degas pelo meio fotográfico residia, sobretudo, nas novas possibilidades do projeto realista propiciadas pela fotografia. Eugenia Parry (1984) escreve que Degas pensou como fotógrafo antes mesmo de fotografar e refletir sobre o fato é essencial para esclarecer como o artista nos ensina a ver. Mais que qualquer outro pintor do século XIX, Degas compreendeu o que significa ver em termos fotográficos e era atraído pela precisão das fotografias que se alastravam ao seu redor. Na contramão de uma representação eloquente em termos 
tradicionais, subvertia o realismo banal por uma filosofia de mise-en-scène calculada. $O$ teatro de Degas é sinônimo de pose.

Fundamentado no treinamento artístico clássico baseado em um estudo completo dos antigos mestres e um conhecedor do repertório do drama clássico de poses para o palco, Degas deliberou sobre esses cenários mundanos. $\mathrm{O}$ artista advertiu que nenhuma arte era menos espontânea do que a sua e construiu seus quadros de aparência espontânea aludindo a esse aspecto peculiar da modernidade onde, como observou Karl Marx em 1856, tudo parece impregnado de seu contrário. Cortar figuras ou animais com a moldura, ampliar partes de figuras de primeiro plano para que gestos apareçam nos cantos, sugerir, como o instantâneo inspirado na fotografia de rua faz hoje, cenas vistas de passagem, sempre eludindo a nossa compreensão completa.

Se em monumentar o efémero, Degas parece referir-se diretamente à instantaneidade fotográfica, ocasionalmente registrada em boulevards e experimentado em estúdios de retratos comerciais, permanece o fato de que essa interpretação do movimento contemporâneo na década de 1870 não apenas antecipou, mas transformou grandemente os efeitos espaciais e psicológicos comuns à fotografia atual. Em contraste com as tendências de instantaneidade, o teatro fotográfico de Degas era como palco da família e dos amigos mais próximos. Muito antes de se ocupar da fotografia, Degas tinha investigado completamente muitos dos mesmos efeitos em seus outros meios gráficos da gravura, água-tinta, litografia e monótipo. Na mente de Degas, a fotografia era outra dessas artes gráficas, naturalmente capaz de compartilhar os mesmos efeitos.

Se as pinturas de Degas às vezes sugerem muitas características formais e psicológicas que os fotógrafos do instantâneo estavam imitando na década de 1890 , suas fotografias também contam o fracasso em uma estrada mais experimental. A luz do dia era muito fácil; Degas fechava as cortinas e solicitava as lâmpadas. E também saia para fotografar após o pôr-do-sol.

Stéphane Mallarmé, poeta simbolista, foi um dos que se submeteu ao teatro fotográfico de Degas ${ }^{5}$. Com Renoir ele permaneceu imóvel por quinze minutos à luz de nove lâmpadas à óleo. O grande apelo do retrato, um dos verdadeiros sucessos fotográficos de Degas, envolve os olhares sustentados dos modelos e sua clara relação uns com os outros, bem como com a figura de Degas, refletida com sua câmera no espelho. Apesar das condições de iluminação deixarem muitos detalhes na sombra, Degas conseguiu provocar de seus atores gestos sutis que emergem da escuridão e falam de uma época. Este retrato, como os outros, propõe contrastes formais e espirituais, escreve Eugenia Parry (1984). Além disso, a imagem também esboça o conflito dos estilos simbolizados pelos participantes. Degas sugere uma renovada relação com o impressionismo (Renoir) e com a imaginação poética do simbolismo (Mallarmé).

Os experimentos continuaram, em um meio admirado geralmente por sua ciência exata, o processo da sugestão. Eles produziam efeitos, que se não estritamente "simbolistas", às vezes se aproximavam da fantasia expressiva da pura imaginação.

Malcolm em (DANIEL, 1998) nos apresenta mais sobre as experimentações do pintor, se referindo a um conjunto de negativos em vidro de Edgar Degas que mostram uma bailarina em várias poses ${ }^{6}$. Esses negativos serviram de modelo para vários desenhos e pastéis de Degas. A sobreposição de imagens positivas a partir destes três negativos mostra a composição das poses (Figura 1) utilizada por Degas como referência para sua obra Danseuses Bleues?.

A fotografia de Degas foi acima de tudo um campo de experimentação e representa uma mistura singular, refletindo diferentes intenções e servindo a propósitos diferentes. Para Eugenia Parry (1984),
[5] A fotografia Pierre-August Renoir and Stéphane Mallarmé (1895), de Edgar Degas, do acervo do MoMA, Nova York, está disponivel em: $<$ www.mom org/collection/ works/48495>

[6] Os três negativos monocromáticos (1895-1896) de Edgar Degas nes seguintes Danseuse le bras tendu, do acervo da Bibliothèque Nationale de France (BnF), Paris, é disponivel em: QzJwjm>.

Danseuse ajustant sa bretelle está sa bretelle esta <https://goo. gl/g3LVgZ>:e gastrgz $\mathrm{e}$ Danseuse ajustant está disponível está disponivel

[7] A obra Danseuses Bleues (1899) de Edgar Degas, do acervo do The Pushkin State Museum of Fine Arts, Moscou está disponível em: <https://g g//8YaBXn 
compreender a fotografia de Degas é entendê-la não como um instrumento de trabalho, à parte, mas integrado em suas preocupações artísticas como um todo e na fotografia em seu entorno, enquanto ele

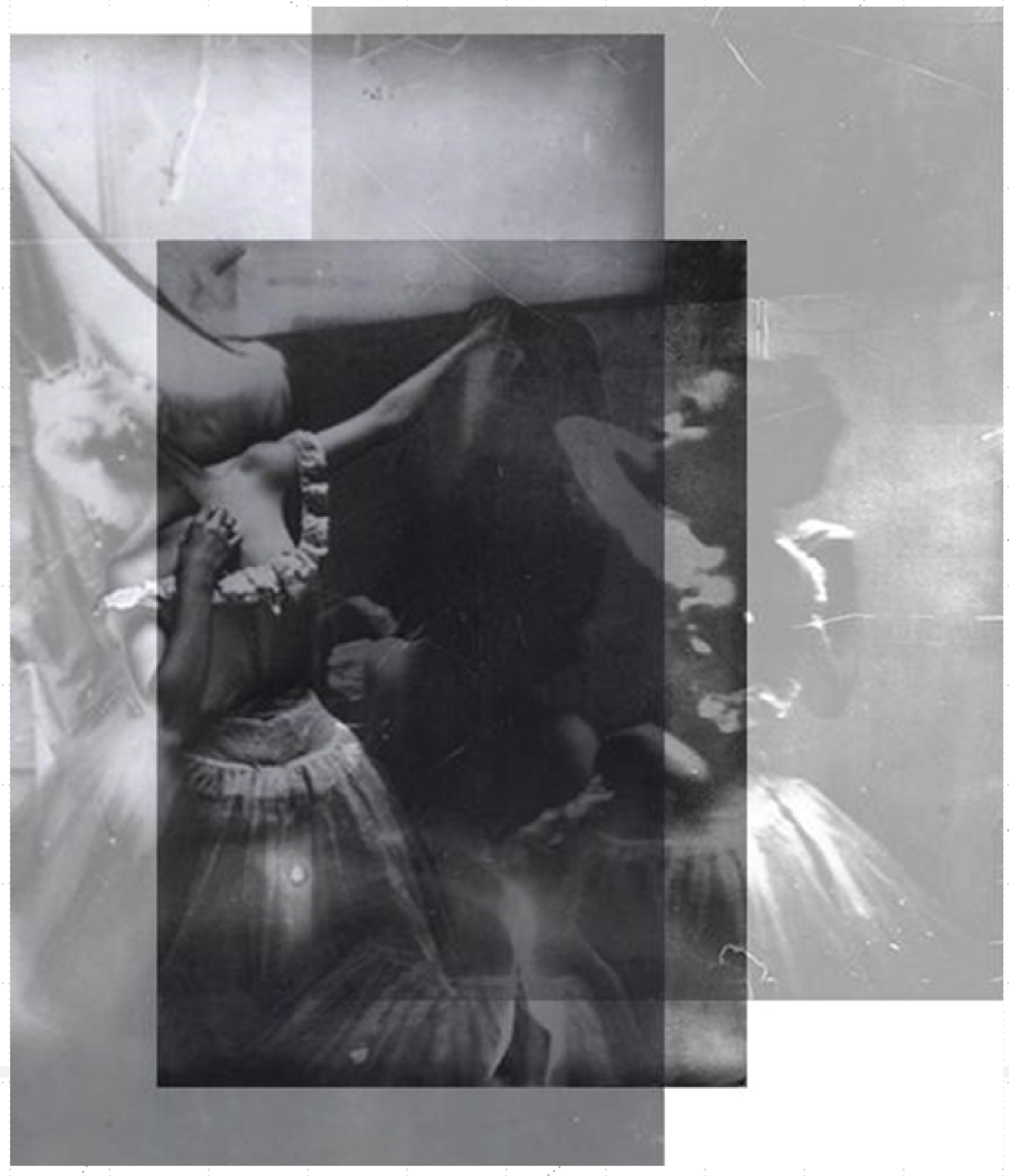

Figura 1 - Sobreposição de positivos a partir dos negativos de Edgar Degas. Manipuląção digital: Autora. se desenvolvia como um artista mais jovem antes de começar a se divertir com a câmera. Sua arena fotográfica com seu conjunto de lâmpadas á óleo era uma sala íntima de teatro, um ambiente perfeito que se resumia em "uma via artificial" que o colocava além do impressionismo

A diversidade da fotografia de Degas reflete a curiosidade devoradora do artista ao longo de sua carreira. Essa diversidade não era apenas necessária, mas justificável. E ele era excepcionalmente amável ao justificá-la no trabalho de seu reverenciado mestre, Ingres. Eugenia Parry escreve:

$$
\begin{aligned}
& \text { De acordo com Moreau-Nétalon, Degas adorava contar } \\
& \text { a história de Ingres, o baluarte da retidão clássica e } \\
& \text { consistência estilística, que foi abordado por dois visitantes } \\
& \text { em uma exposição de seu trabalho. Quando um criticou as } \\
& \text { discrepâncias estilísticas de uma pintura para outra, Ingres } \\
& \text { replicou: "Senhor, tenho mais de um pincel! Não é delicioso?" } \\
& \text { E Degas ria, falando a frase repetidamente. (PARRY, 1984, p. } \\
& \text { 482, tradução nossa). }
\end{aligned}
$$

\section{ENSAIO FOTOGRÁFICO - LA DANSEUSE DE DEGAS}

Com inspiração em Edgar Degas, sua obra, sua liberdade artística para a experimentação, sua filosofia de mise-en-scène, e procurando trazer para a realidade fotográfica algumas imaginações relacionadas ao pintor, realizou-se um ensaio fotográfico na cidade de Paris.

A série de fotografias La danseuse de Degas, resultado dessa experimentação, buscou criar um realismo em diálogo com a pintura, e incorporou questões relacionadas ao tempo entre passado e presente, além da sugestão de uma narrativa, agregando ao conjunto a duração de tempo do ato fotográfico, decomposto pelo instante de cada imagem da série. 
Na imaginação da fotógrafa, era tanta a realidade que o pintor procurava trazer para suas obras, como na escultura Petite danseuse de quatorze ans $(1881)^{8}$ que recebeu laço de fita nos cabelos e saia reias, que uma das bailarinas de sua obra Classe de danse (18731876) sai da tela e se torna de fato real (Figura 2). Entre a imagem real da bailarina e o quadro pintado por Degas ocorre uma diferença temporal que causa certa perturbação em uma visão simultânea no mesmo espaço. As fotografias da jovem bailarina francesa junto às obras do pintor foram feitas no Musée d'Orsay.

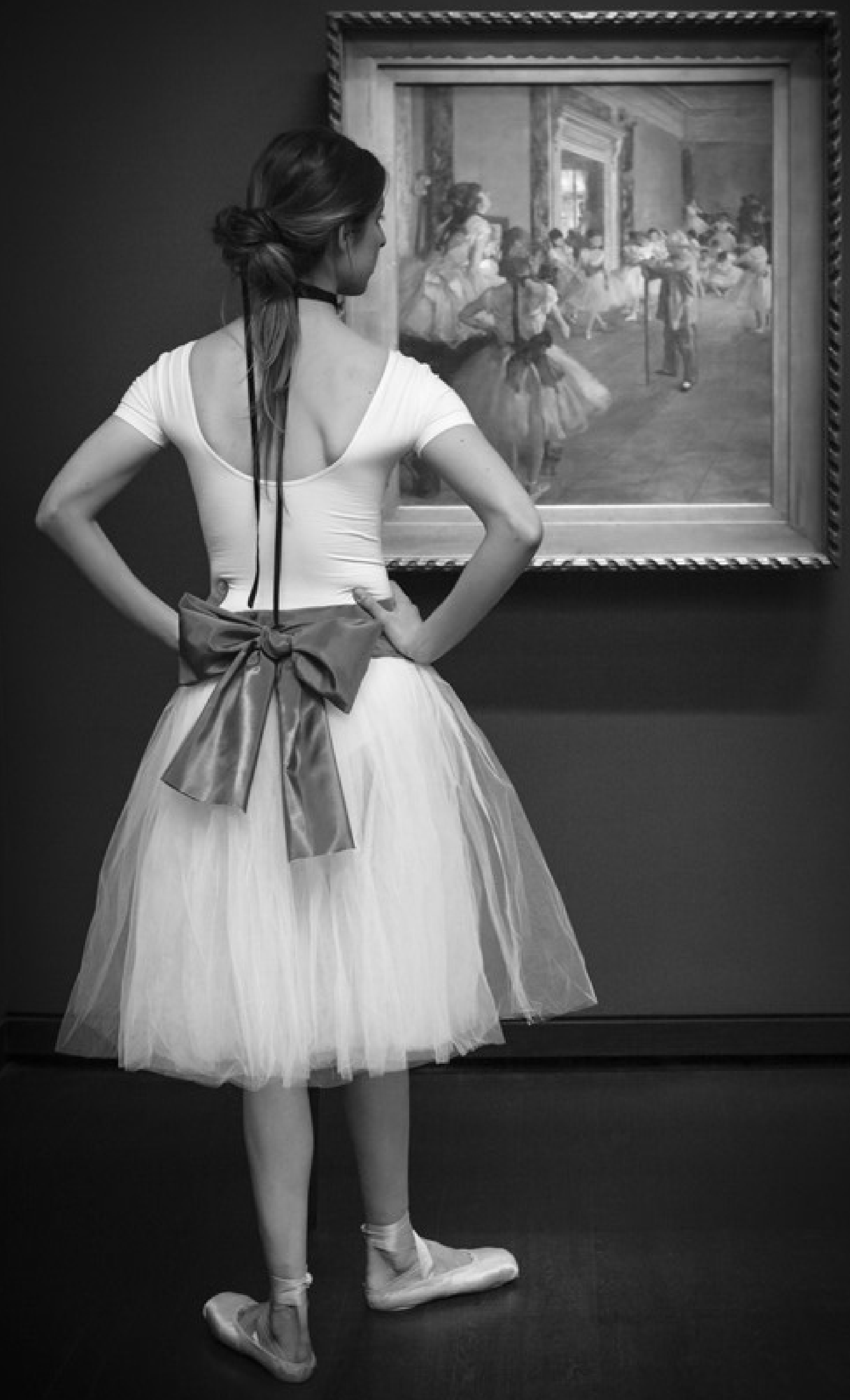


A criatura vai, então, em busca do seu criador, e finalmente se reencontram, porém em posições inversas: ela, real; ele, pintura. A mesma diferença temporal através dos meios que se confundem e se sobrepõem no espaço, a bailarina e a obra Portrait de l'artiste (1855) de Edgar Degas (Figura 3).

PARALELO31

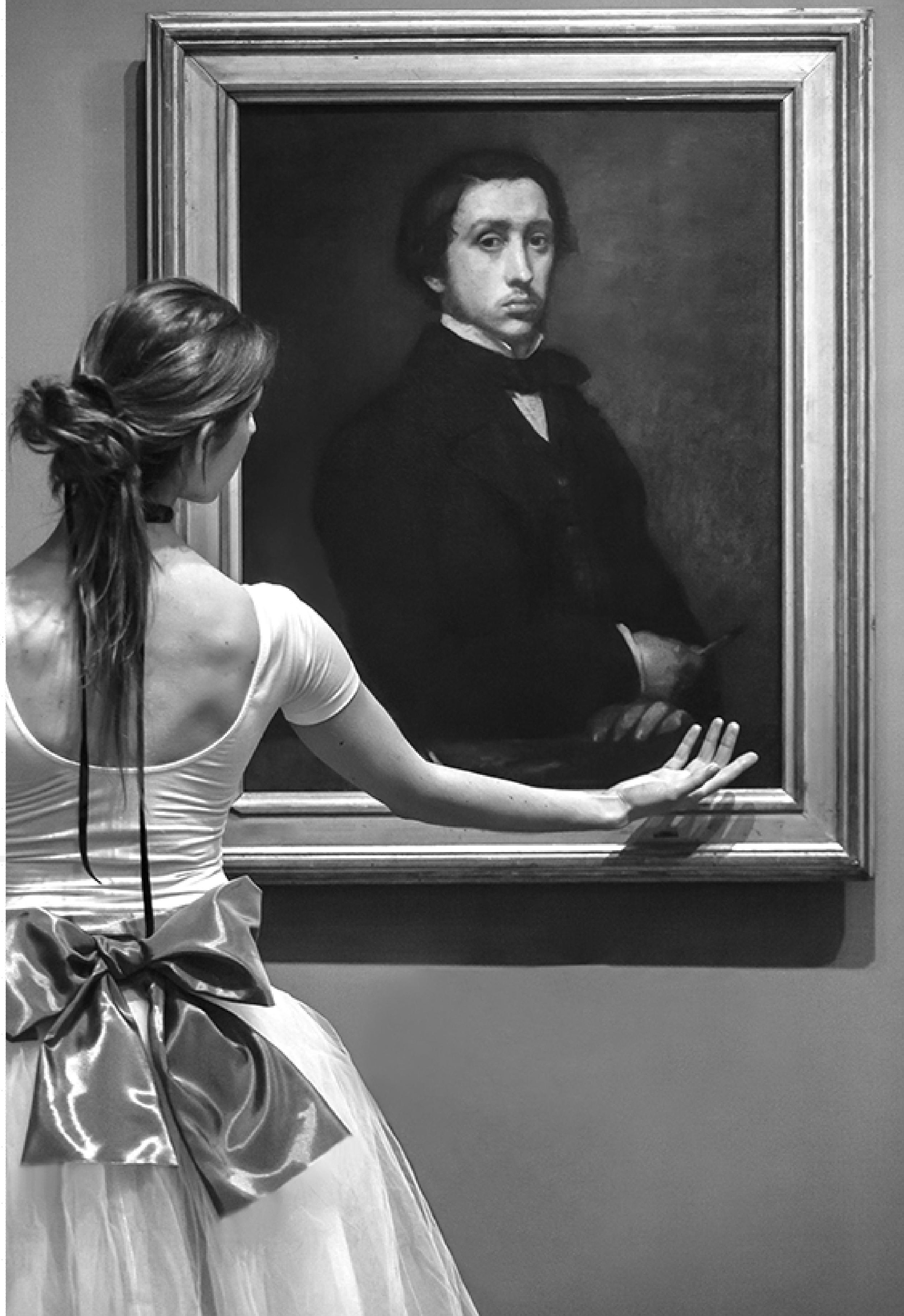



lizado na imagem da bailarina que tem ao fundo um relógio disposto de forma invertida, e que assim anda para trás no tempo (Figura 4).

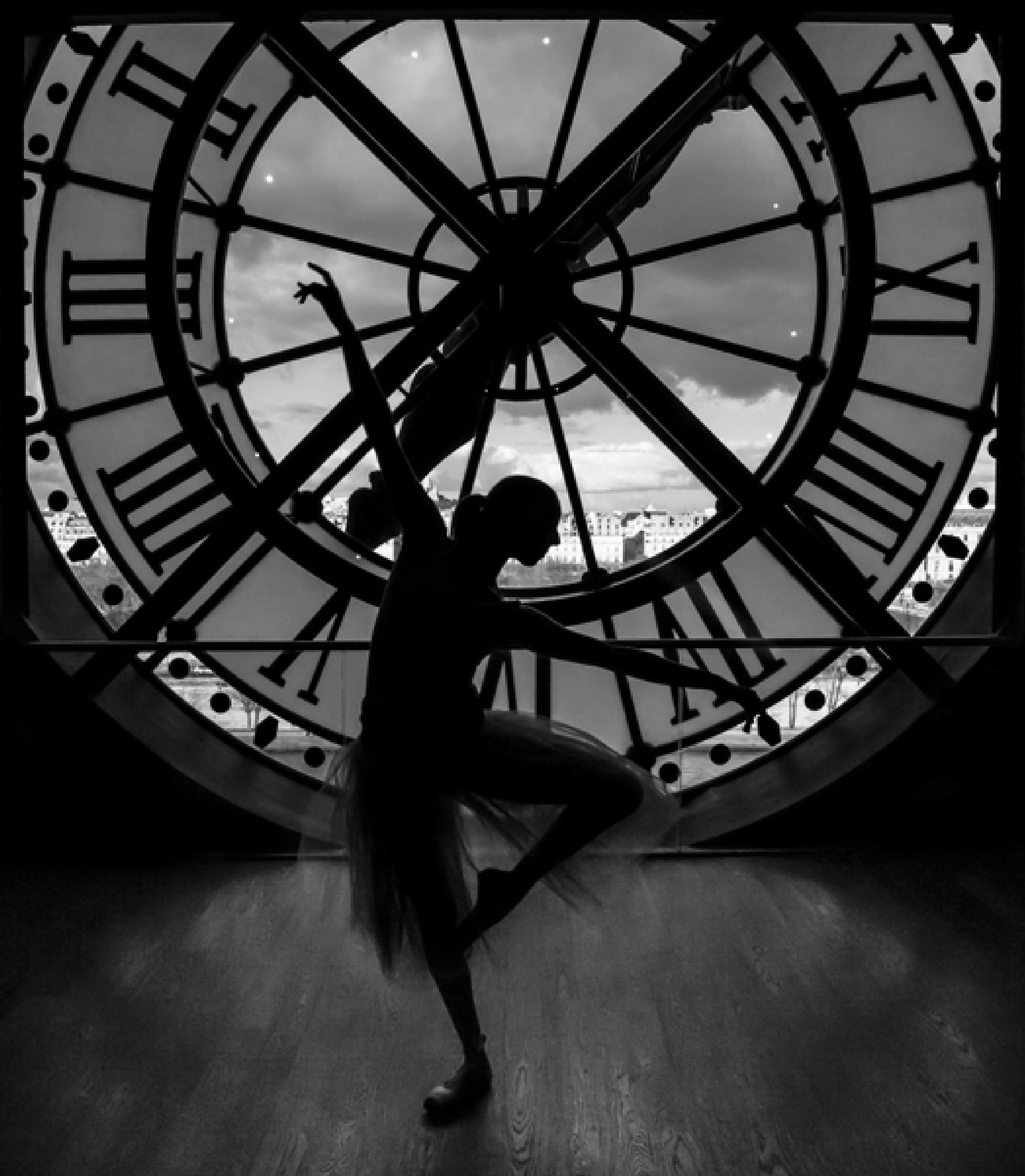


Junto ao relógio do Musée d'Orsay, a bailarina visualiza a cidade de Paris, e ao longe Montmartre, o bairro onde Degas e vários artistas moravam, e onde os impressionistas se reuniam no século XIX, cenário retratado em várias obras destes artistas (Figura 5). 
E compreendendo a liberdade que 0 artista sempre teve na criação de sua arte, a bailarina se liberta não apenas da tela, mas também do ambiente do museu, e sai pelas ruas de Paris até Montmartre, nos lugares onde o criador costumava ir, em busca também de sua liberdade. Entre esses lugares, o café da Place Pigale onde os impressionistas se reuniam (Figura 6)

DARALELO3!

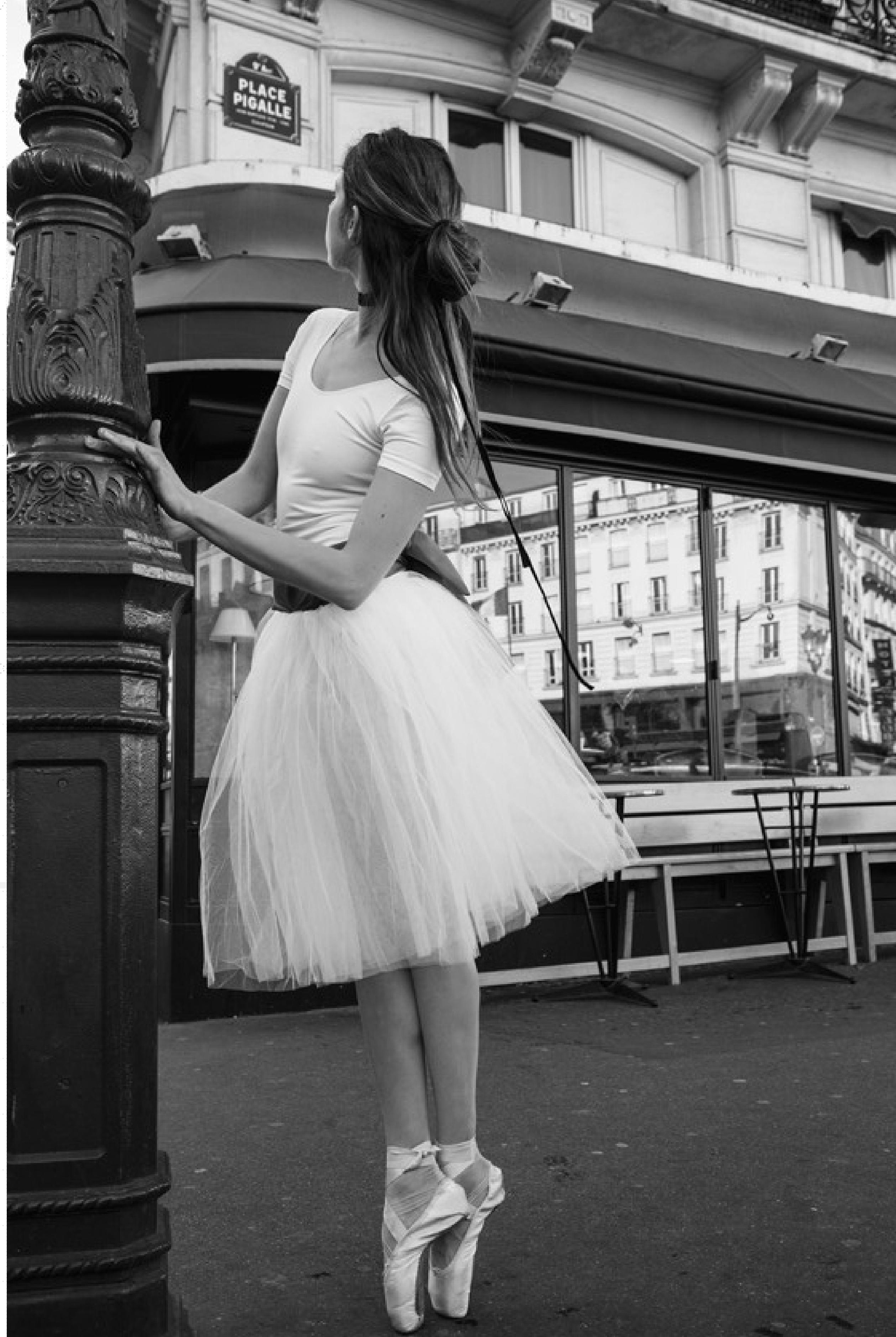




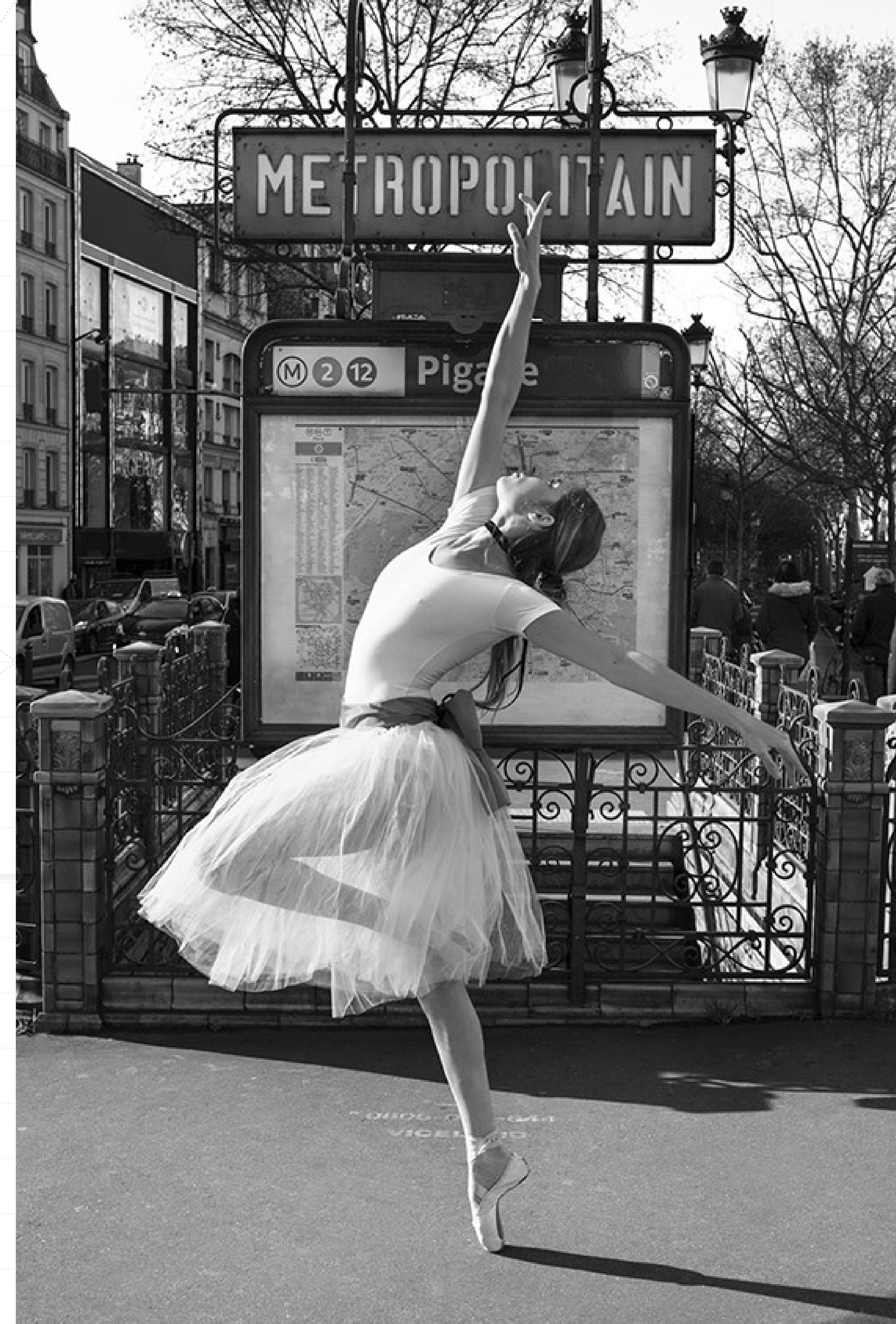


O processo de criação do experimento procurou explorar todas as fases do processo fotográfico, e envolveu desde a pré-produção, com o estudo sobre o pintor, sua vida e obra, a escolha das locações para melhor representar a narrativa desejada e a preparação do figurino da bailarina com itens que remetessem à pintura de Degas, até a direção da modelo no ensaio fotográfico, e o período de pós-produção, com a seleção e edição das fotos, optando-se pelas imagens em preto em branco por melhor representarem a relação com a fotografia do século XIX.

A série fotográfica La danseuse de Degas foi apresentada pela primeira vez na exposição coletiva Paragem na Pinacoteca Barão de Santo Ângelo do Instituto de Artes da UFRGS em 2017, e representa uma homenagem da autora a Edgar Degas no ano em que se completam cem anos de falecimento do pintor.

Concluímos que, além do corte temporal ser incapaz de anular por completo a sugestão de tempo e movimento nas imagens fotográficas, a relação e o significado do tempo no imenso léxico da imagem fotográfica são múltiplos e se expressam de várias formas. A fotografia conjuga relações perceptivas que vão além do tempo histórico. $E$ através da subjetividade, a narrativa imagética estabelece um campo profuso que tangencia a criação, a percepção e a memória.

O ensaio realizado, tendo o universo da dança como motivo, mas agregando também a narrativa com o referencial das pinturas de Degas, permitiu incorporar tanto a captação das façanhas técnicas e virtuosas do corpo em movimento, como também a emoção dos olhares e gestos da bailarina, enriquecendo as possibilidades de intenção artística na série de fotografias realizada.

A concepção da imagem, e especialmente da imagem fotográfica, se alterou, ou se ampliou, ao longo de sua história. Percebendo como Degas, no século XIX, já compreendia tão bem a fotografia e todas as suas possibilidades, e com inspiração na sua liberdade da experimentação e de outros artistas, continuamos nossa pesquisa, lançando-nos a novas possibilidades de representação e expansão do tempo do fazer fotográfico em nosso processo de criação artística.

\section{REFERÊNCIAS}

BELTING, Hans. Antropologia da Imagem. Lisboa: Kkym, 2014.

DANIEL, Malcolm. Edgar Degas: Photographer. New York: The Metropolitan Museum of Art, 1998

ENTLER, Ronaldo. A fotografia e suas representações do tempo. In. Revista Galáxia, São Paulo, n. 14, p. 29-46, dez 2007.

FLORES, Laura Flores. Fotografia e Pintura: dois meios diferentes? São Paulo: WMF Martins Fontes, 2011

GASTALDONI, Dante. 0 tempo e os tempos na fotografia. São Paulo: Senac,

PARRY, Eugenia. Edgar Degas's Photographic Theater. In: Degas, form and space. p. 451-486. Centre Culturel du Marais. Paris: Guillaud, 1984

SOULAGES, François. Estética da Fotografia: perda e permanência. São Paulo: SENAC, 2010 